\title{
Multi-objective simultaneous optimal planning of electrical vehicle fast charging stations and DGs in distribution system
}

\author{
Gurappa BATTAPOTHULA $^{1}$ (D), Chandrasekhar YAMMANI ${ }^{1}$, \\ Sydulu MAHESWARAPU ${ }^{1}$
}

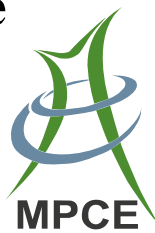

\begin{abstract}
The large-scale construction of fast charging stations (FCSs) for electrical vehicles (EVs) is helpful in promoting the EV. It creates a significant challenge for the distribution system operator to determine the optimal planning, especially the siting and sizing of FCSs in the electrical distribution system. Inappropriate planning of fast EV charging stations (EVCSs) cause a negative impact on the distribution system. This paper presented a multiobjective optimization problem to obtain the simultaneous placement and sizing of FCSs and distributed generations (DGs) with the constraints such as the number of EVs in all zones and possible number of FCSs based on the road and electrical network in the proposed system. The problem is formulated as a mixed integer non-linear problem (MINLP) to optimize the loss of EV user, network power loss (NPL), FCS development cost and improve the voltage profile of the electrical distribution system. Non-dominated sorting genetic algorithm II (NSGA-II) is used for solving the MINLP. The performance of the proposed technique is evaluated by the 118-bus electrical distribution system.
\end{abstract}

CrossCheck date: 18 October 2018

Received: 18 August 2018/Accepted: 18 October 2018/Published online: 4 January 2019

(C) The Author(s) 2019

Gurappa BATTAPOTHULA

gurubattapothula@student.nitw.ac.in

Chandrasekhar YAMMANI

chandrayammani@nitw.ac.in

Sydulu MAHESWARAPU

msydulu@nitw.ac.in

1 National Institute of Technology, Warangal, India
Keywords Electrical vehicles (EVs), Fast charging stations (FCSs), Non-dominated sorting genetic algorithm II (NSGA-II), Renewable energy sources

\section{Introduction}

One of the greatest challenges in developed and developing countries is reducing the greenhouse gas emissions due to fossil fuel vehicles with internal combustion engines (ICEs) and electrical power generation from fossil fuels. The most promising pathway to energy security and reducing emissions is facilitating the global deployment of 20 million electric vehicles (EVs) by 2020 and the use of renewable distributed generation (DG) systems [1]. If this rate is maintained to 2050, EVs will replace $62 \%$ of fleet vehicles [2]. The EVs cause lower emission and require less energy for transit for a mile, as compared to ICEs. Hence they are required as a promising tool to combat the challenges related to energy sustainability and global warming. Therefore, governments, automobile companies, energy agencies, etc., have made significant efforts to enhance the popularity of EV [3].

Many researchers focus on optimal placement and sizing of EV charging stations (EVCSs) [4-9] with different straggles. Inappropriate placing and sizing of EVCS cause a negative impact in the distribution system with an increase in network power losses (NPLs) and more degradation in voltage profile. In [5], Fox et al. explained the standard levels of EV charging standards, the level-1 and level-2 EV charging requires hours of time to charge EVs, but direct current fast charging stations (FCSs) needs 15-20 minutes to charge up to rated SOC of the EVs.

Reference [6] explained the significance of workplace and public charging stations (CSs) to reinforce and fulfill 
the gaps from home-based charging in dense EVs populated urban areas. In [7], a mixed integer non-linear programming (MINLP) problem is formulated to solve the optimal planning (placement and sizing) of FCS, with the account of the cost of CS, electrification and electrical power loss in the distribution system. In [8], a two-step screening method was developed with the account of environmental factors and the service radius of EVCSs, to optimally place of CSs. A modified primal-dual interior point algorithm was proposed to determine the size of CSs. In [9], the EVs charging demands on the transportation network is capture by the capacitated-flow refueling location model. The optimal planning of EV FCSs is considered both the transportation and electrical constraints; it is solved by using deterministic branch-andbound methods.

In [10], an efficient method was proposed for the optimal planning of CSs, especially battery swap CSs in the distribution network based on life-cycle cost analysis. In [11], a two-stage procedure has been developed to determine the optimal size and location of plug-in hybrid electric vehicle (PHEV) CSs to maximize the distribution system manager (DSM) benefit with distribution, traffic network topologies and the driving behavior of EV owners. In [12], the authors considered the power distribution network, traffic network and EV owners driving behavior to formulate a multi-objective CS planning method. The objectives in multi-objective optimization are to minimize power loss and voltage deviation in the distribution network and the maximization of the service capability of CS. To solve the CS planning an efficient cross-entropy method is used and obtains the optimal Pareto solutions. A new data-envelopment method is then used to determine the optimal CS location and its size simultaneously. In [13], the impact of high penetration of PHEVs on the distribution systems has been analyzed. In [14], the state of California uses freeway exits and highway intersections as moderate candidate CS locations and also solves the optimization problem to optimize the number of CS.

The rapid increase of EV population requires efficient charging facilities like FCS. EV charging at home is an alternative way but it requires too much time. Therefore, the CS with high voltage is necessary for the convenience of EV user, because it can charge the EVs at faster rate i.e., 12 times faster than charging at home [15]. The higher adoption of EVs may cause a potential impact on the distribution grid. Reference [16] explained the concept of un co-ordination charging of EVs and its impact on distribution system like high peak demand, more NPL, and needs a significant infrastructure.

Even though CSs have many advantages, they could even jeopardize the system operation, when the size and location of CSs are not systematically decided. In [17], a realistic model was developed for the fast CS placement problem in cities like Singapore considering the interactions among CSs, EV users charging activities, traffic congestion and queuing time. In [18], a fuzzy technique was applied for selecting the most sustainable site of EVCSs considering environmental, economic and social criteria. An evaluation index has been developed for the optimal location of EVCS with the account of environmental, social and economic criteria in the electrical distribution system. In [19], a heuristic algorithm has been applied to determine the optimal planning of CSs by considering the initial investment cost and distribution system power quality parameters as in the objective function, in the city of Allahabad in India. In [20], the moderate location of EVCS is determined by using the integrated multiple criteria decision making approach based on grey decision making trial and evaluation laboratory and uncertain linguistic multi-objective optimization. In recent literature, there are two papers considered the simultaneous optimal planning of CSs and DG power unit in the distribution system. The first one [21] is joint planning of EVCS and distributed photovoltaic generation in the distribution system is solved by using an accelerated generalized Benders decomposition algorithm. A multidisciplinary approach is proposed with the account of investment cost (the fixed cost of EVCS and PV power plant, variable cost for adding an extra charging spot in EVCS and per unit PV panel in PV power plant) and maintenance cost (the cost of electricity, penalty for unsatisfied PEV charging demand and penalty for undesirable voltage deviation), in order to identify the location and size of EVCS and PV plant. Reference [22] presented an optimization model for the optimal planning of DG units, EVCSs, and energy storage systems within the electrical distribution system. The optimal planning of CSs, renewable DG units and energy storage systems in the distribution system is solved by using a second-order conic programming problem, in order to optimize the active power loss and penetration of DG, EVCS and energy storage systems within the distribution system.

In the majority of previous work, the authors consider the optimal placement of CSs only, it strongly affects distribution system power losses and voltage profile. Only a few papers $[21,22]$ the authors considered the simultaneous optimal planning of CSs and DG power units in distribution system but in those papers does not consider the specific energy consumption of EV user loss, voltage deviation, investment and maintenance cost of CS and DG power units.

Thus this paper newly presents the simultaneous placement of both FCSs and DGs to minimize the investment cost of CSs and DG units, specific energy consumption of EV user loss, voltage deviation and power losses in the 
coupled electrical distribution system and transportation network.

The major contributions of this paper are presented step by step as follows:

1) Identifying the optimal number of FCS and their locations by considering the EV users behavior, distribution system losses and electrical distribution system bus voltage profile.

2) Finding the optimal planning of DGs by considering optimal FCSs load to improve system bus voltage profile and minimizing the distribution system loss.

3) Placing the FCSs and DGs simultaneously with the account of system constraints and EV user behavior for better system bus voltage profile and minimal power losses.

4) As per our knowledge, first time, an efficient multiobjective non-dominated sorting genetic algorithm II (NSGA-II) is proposed for finding Pareto-optimal solution of the optimal number of FCSs, DGs and its simultaneous location and sizing for minimizing station development cost (SDC), specific energy consumption of EVs, distribution system bus voltage deviation and power losses in a coupled electrical distribution system and transportation network.

The paper is organized as follows: the impact of FCS load in the distribution system and formulation of the objective function are briefly explained in Section 2. Section 3 describes the multi-objective NSGA for the taken system. The results and analysis are explained in Section 4 and some conclusions are drawn in Section 5.

\section{Problem formulation}

This section presents the formulation of the objective function to minimize FCS development cost, cost of specific energy consumption of EVs, Electrical NPL cost, DG power generation cost and maximum voltage deviation (MVD) in the electrical distribution network.

For determining the optimal FCS location and EVs position, the proposed approach uses an area with the number of zones as shown in Fig. 1. The study area divided into zones as $z_{1}, z_{2}$, and $z_{3}$ for which the EVs data are

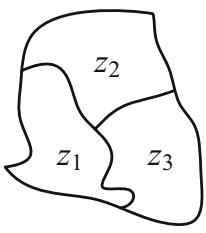

Fig. 1 Proposed area with zones available. EV population in each zone is distributed and it is assumed that the EV population in each zone is located at the geographic center of the zone.

Assume that in a considered day, the total number of EVs (TEV) in the study area is charged by the FCS. The TEV in study area calculated as:

$N_{T E V}=\sum_{z=0}^{n_{z}} N_{E V, z}$

where $N_{E V, z}$ is the number of dedicated EVs in zone $z$, i.e., all dedicated vehicles are regular costumers of that zonary FCS and $n_{z}$ is the number of zones in the considered study area.

\subsection{SDC}

The considered $j^{\text {th }}$ SDC mainly depends on the number of charging connectors in $j^{\text {th }} \mathrm{FCS}, S(j)$, and its rated capacity $\left(P_{C}\right)[7]$.

$S D C(j)=C_{\text {init }}+25 C_{\text {lan }} S(j) N_{Y}+C_{\text {con }}(S(j)-1) P_{C}$

where $C_{\text {init }}$ is the station fixed cost; $C_{\text {lan }}$ is the yearly land rental cost; $C_{c o n}$ is the charger development cost of $j^{\text {th }}$ station; $N_{Y}$ is the number of years in the study period; $S(j)$ is the number of charging connectors in $j^{\text {th }}$ FCS.

The number of connectors in the $j^{\text {th }} \mathrm{CS} S(j)$ is calculated as:

$S(j)=\sum_{z=1}^{n_{z}}\left(\max \left(C_{P E V}\right) \cdot N_{E V, z} \cdot S E(z, j)\right)$

where the variable $C_{P E V}$ is a set having the probability of EV charging in the hour $(h)$ of the day; $S E(z, j)$ is binary decision variable, equals to 1 if EVs in the zone $z$ is charged by the station $j$, otherwise, zero. The selection of EVs in the zone $z$ to $j^{\text {th }} \mathrm{CS}$ depends on the minimum distance between $j^{\text {th }} \mathrm{CS}$ to zone $z$ as compared to the other CSs.

The area required for each connector and the minimum clearance between the connectors are $25 \mathrm{~m}^{2}$ and $3 \mathrm{~m}$ respectively. The rating of charging connector varies in the range of 50-250 $\mathrm{kW}$ based on the connector technology. The capacity of $j^{\text {th }}$ FCS is determined as:

$C_{F C S}(j)=S(j) P_{C}$

\subsection{EV user cost (EVUC)}

The EV user should drive a certain trajectory to reach to the FCS. EVUC represents the cost associated with the energy consumed by EV to reach the FCS. For EVs located in zone $z$, the EVUC to reach nearest FCS for being charged at $\mathrm{CS} j, C_{E V U}(z, j)$ is calculated as follows [23]: 
$C_{E V U}(z, j)=d(z, j) \cdot S E C \cdot \sum_{h=1}^{24} C_{P E V}(h) \cdot E V(z) \cdot C_{E P}$

where $d(z, j)$ is the distance between zone $z$ and CS $j$; SEC and $C_{E P}$ are the specific energy consumption of EVs and electricity price during hour $h$. The distance to displacement ratio depends strongly on the optimality of the road network in the study area. For an optimal road network, the distance approaches the displacement. Hence, choosing the displacement rather than distance in this approach to obtained CSs are still optimal for the optimal road network.

\subsection{NPL cost}

The higher FCS charging demand increases the line and substation loading. It causes an increase in distribution system losses. The distribution system loss has a nonlinear relationship with the system loading. The variable distribution system loss is significant due to EV charging demand, hence the precise calculation of electrical grid loss is required, with the account of the variation in grid load.

The distribution NPL cost during one year in all seasons is calculated as follows:

$C_{N P L}=\sum_{\omega=1}^{n_{\omega}} \sum_{h=1}^{24} L_{T P}(h, \omega) N_{T H}(\omega) C_{E P}$

where $n_{\omega}$ is the number of seasons; $L_{T P}$ is the total electrical power loss including FCS load; and $N_{T H}$ is the total number of hours in each season of the year.

The added power loss (APL) for hour $h$, during the season $\omega$ due to FCS charging demand, is calculated as follows [23]:

$L_{A P}(h, \omega)=L_{T P}(h, \omega)-L_{G P}(h, \omega)$

where $L_{T P}$ is the total power loss including FCS load; and $L_{G P}$ is the gross power loss with conventional load (without FCS load).

\subsection{DG power cost}

The DG power cost $C_{D G}$ consists of investment $\operatorname{cost} C_{I}$, operation cost $C_{O P}$ and maintenance cost $C_{M}$ of DGs. Investment cost contains unit construction, installation and essential equipment cost. Operation cost includes the cost of replacing components during their technical lifetime and maintenance cost contains costs of renewing, repairing, and restoring unit equipment in case of necessity [24-26].

$C_{I}=\sum_{g=1}^{N_{D G}}\left(P_{D G, g} C_{I N V, g}\right)$
$C_{O P}=\sum_{y=1}^{N_{Y}} \sum_{g=1}^{N_{D G}}\left(P_{D G, g} T_{h} C_{O P}^{\prime}\left(\frac{1+R_{I N F}}{1+R_{I N T}}\right)^{N_{Y}}\right)$

$C_{M}=\sum_{y=1}^{N_{Y}} \sum_{g=1}^{N_{D G}}\left(P_{D G, g} T_{h} C_{M}^{\prime}\left(\frac{1+R_{I N F}}{1+R_{I N T}}\right)^{N_{Y}}\right)$

$C_{D G}=C_{I}+C_{O P}+C_{M}$

where $P_{D G, g}$ and $C_{I N V, g}$ are the rated real power and inverter cost of $g^{\text {th }}$ DG unit; $C_{O P}^{\prime}$ and $C_{M}^{\prime}$ are the operating cost and maintenance cost of each DG unit; $R_{I N F}$ and $R_{I N T}$ are the inflation rate and interest rate of each DG unit; $T_{h}$ and $N y$ are total number of hours in a year and total the number of years; and $N_{D G}$ is the number of DGs considered for the study. The above-mentioned parameters required to calculate DG power cost are taken from [26].

\subsection{MVD}

Inappropriate placement of FCSs and DGs causes voltage instability in the distribution network. Both of over and under voltages effects the power supply quality. In this paper, the bus voltage deviation (p.u.) in four seasons for 24 hours is considered. The MVD of electrical distribution system is calculated as:

$\max v_{d e v}=\max \{1-\min (v(i))\} \quad \forall i=1,2, \ldots, n$

where $\min (v(i))$ is the minimum per unit voltage at bus $i$; and $n$ is the number of buses in a considered electrical distribution system.

\subsection{Objective function}

$\min \left\{\sum_{j=1}^{N_{F C S}} S D C(j)+\sum_{k=1}^{N_{T E V}} C_{E V U}(k)+C_{N P L}+C_{D G}+\max v_{d e v}\right\}$

where $N_{F C S}$ is the optimal number of FCS obtained from the optimization algorithm. The objective function is to minimize the total cost related to FCS, DGs and NPL cost; and minimize the bus voltage deviation of the electrical distribution system by meeting the following constraints.

\subsection{System constraints}

The multi-objective optimization function (13) is bounded to the power balance, voltage, thermal and DG power generation constraints as explained in [27-29].

At least one CS should be selected to recharge the EVs in the study area is as follows: 
$\sum_{j=1}^{N_{P C}} X(j)>0 \quad \forall c=1,2, \ldots, N_{P C}$

where $X(j)$ is the Binary decision variable, which is equal to 1 if $j^{\text {th }}$ CS is selected, otherwise, zero; and $N_{P C}$ is the number of possible CSs.

At least one charging connector should be considered for each selected CS, as follows:

$S(j) \geq 0 \quad \forall j=1,2, \ldots, N_{P C}$

EVs in each zone should select one optimal FCS based on the displacement between $j^{\text {th }}$ CS and zone $z$.

$\sum_{z=1}^{n_{z}} S E(z, j) X(j)=1$

\section{NSGA-II for simultaneous optimal planning of FCSs and DGs}

NSGA-II is one of the most popularly used multi-objective optimization algorithm in different applications, due to its high performance for finding a set of Pareto solutions. The performance of NSGA-II is majorly depends on its evolution operators, mainly including the non-dominated sorting, crowing distance operator. Initially, a random parent population $P_{t}$ of size $N$ is generated, then it is sorted based on nondomination. Assign a rank to each solution based on its fitness value. The binary tournament selection, recombination, and mutation operators are used to generate offspring population $Q_{t}$ of size $N$. Get the combined population $R_{t}\left(P_{t} \cup Q_{t}\right)$ of size $2 N$. Then, the population $R_{t}$ is sorted according to its non-domination. The solutions in the first front $F_{1}$ are of good solutions as compared to the other front solutions in the combined population. If the size of the first front $\left(\mathrm{F}_{1}\right)$ is less than $N$, then choose all populations of front $\mathrm{F}_{1}$ for the new population $P_{t+1}$. Then the remaining members of the new population are chosen from subsequent fronts in order of their ranking. To choose exact $N$ members for new population $P_{t+1}$ from the subsequent fronts we use crowding distance operator [30]. The crowding distance operator guides the selection process at various stages of the algorithm, to determine the density of solutions that are surrounding a particular solution [31].

The best parameter values for the NSGA-II which are selected through multiple test simulation runs for the optimal planning of FCSs and DGs in a coupled electrical distribution and transportation network are given in Table 1.

In NSGA-II, the nondominated sorting technique and crowding distance operator is used to rank the individual populations and to get good spread in the optimal Pareto front respectively. The selection operator is to "select the
Table 1 Best NSGA-II parameters for optimal planning of FCSs and DGs

\begin{tabular}{ll}
\hline NSGA-II parameters & Values \\
\hline Population size $(N)$ & 100 \\
Number of iterations $\left(N_{i t e}\right)$ & 400 \\
Crossover probability $\left(P_{c}\right)$ & 0.8 \\
Mutation probability $\left(P_{m}\right)$ & 0.33 \\
\hline
\end{tabular}

best and discard the rest" from a population keeping the population size constant. The crossover operator is used to create new solutions from the existing solutions available in the mating pool after applying selection operator. Mutation is the occasional introduction of new features in to the solution strings of the population pool to maintain diversity in the population. The flowchart for optimal planning of FCSs and DGs in a coupled electrical distribution system and transportation network with the NSGAII algorithm is shown in Fig. 2, where $F_{\text {ront }}$ describes the variation of number of fronts in the multi-objective optimization; $N_{\text {ite }}$ is the iterative variable varies from 1 to maximum number of iterations; and $N_{i t e, \max }$ is the maximum number of iterations.

\section{Simulation results and observations}

To analyze the effectiveness of the proposed optimal planning of FCSs and DGs in a coupled electrical distribution and transportation network, the following proposed test system and three scenarios with multiple case studies are considered in this paper.

\subsection{Proposed system data}

To test the proposed methodology, a study area of $720 \mathrm{~km}^{2}$ surface has been considered. The study area consists of 180 zones, and each zone has an equal area of $4 \mathrm{~km}^{2}(2 \mathrm{~km} \times 2 \mathrm{~km})$.

Figure 3 presents the assumed EV population in each zone of the study area. The total population in the study area is 1632, among the total EVs population only some probability of EVs is charging in each hour during a day. The 118-bus electrical distribution system is assumed on the study area for electrical power supply.

The percentage of electrical power load variation during the day for different seasons is taken from [25]. The base values of 118-bus distribution system are $10 \mathrm{MVA}, 11 \mathrm{kV}$ and the total real and reactive power load on the system is 22.71 MW and 17.041 Mvar. Figure 4 shows the single line 


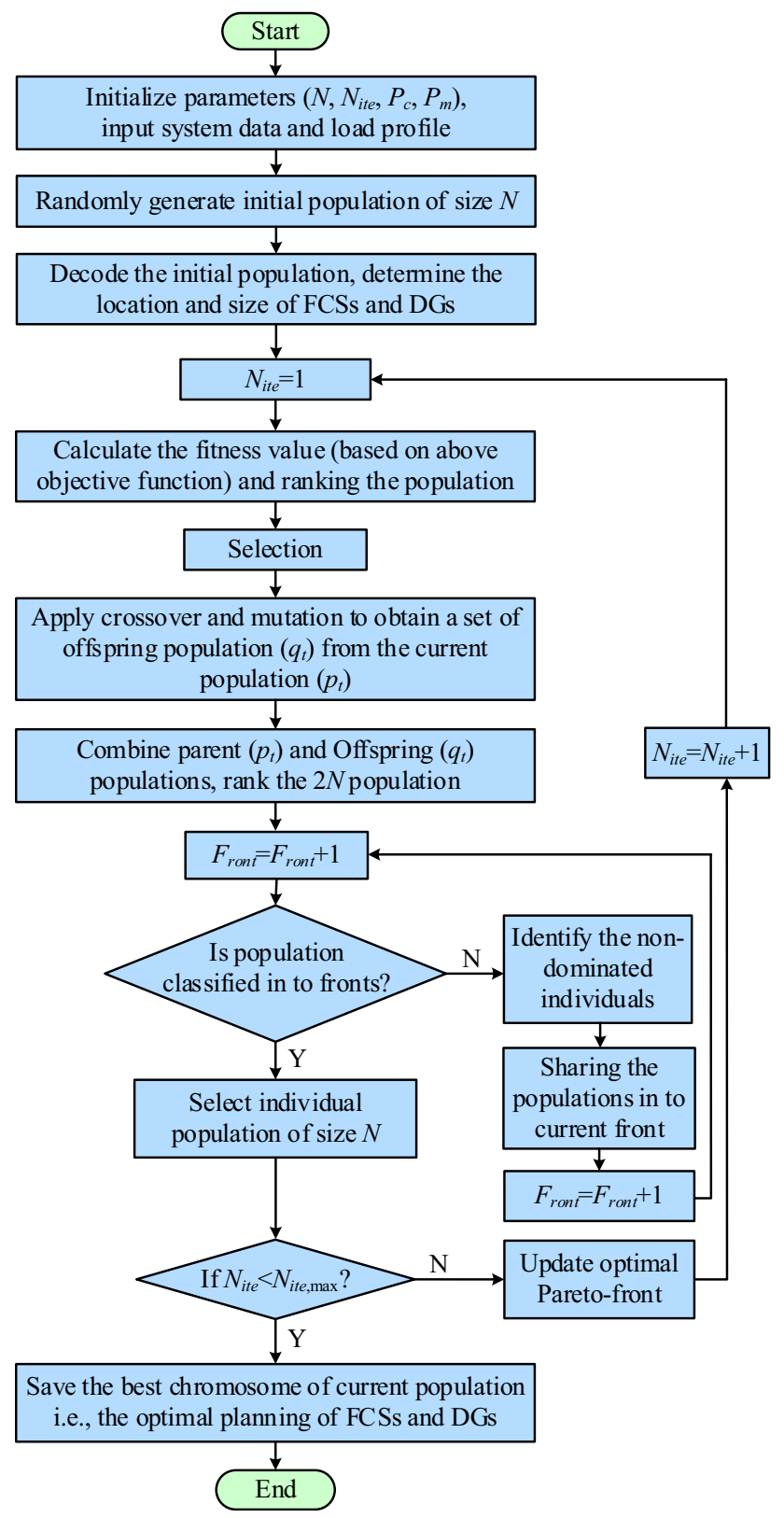

Fig. 2 NSGA-II flow chart

\begin{tabular}{|l|l|l|l|l|l|l|l|l|l|l|l|l|l|l|}
\hline 0 & 3 & 5 & 3 & 4 & 6 & 4 & 0 & 0 & 3 & 7 & 5 & 6 & 4 & 0 \\
\hline 3 & 5 & 4 & 6 & 4 & 6 & 7 & 8 & 7 & 9 & 8 & 7 & 5 & 6 & 4 \\
\hline 7 & 11 & 16 & 9 & 9 & 13 & 12 & 10 & 11 & 14 & 17 & 6 & 9 & 5 & 3 \\
\hline 6 & 1 & 7 & 15 & 16 & 17 & 17 & 9 & 15 & 7 & 14 & 17 & 9 & 15 & 1 \\
\hline 4 & 6 & 9 & 10 & 8 & 16 & 16 & 14 & 0 & 14 & 16 & 11 & 7 & 9 & 7 \\
\hline 0 & 13 & 14 & 10 & 16 & 14 & 19 & 15 & 17 & 14 & 12 & 8 & 15 & 9 & 4 \\
\hline 7 & 11 & 0 & 16 & 16 & 17 & 13 & 18 & 17 & 15 & 9 & 19 & 12 & 8 & 0 \\
\hline 4 & 9 & 15 & 14 & 12 & 11 & 4 & 16 & 19 & 9 & 12 & 17 & 17 & 12 & 6 \\
\hline 8 & 13 & 14 & 19 & 17 & 15 & 17 & 0 & 13 & 12 & 11 & 13 & 9 & 15 & 8 \\
\hline 3 & 12 & 9 & 16 & 13 & 14 & 9 & 14 & 16 & 15 & 17 & 16 & 15 & 13 & 3 \\
\hline 0 & 6 & 7 & 8 & 7 & 5 & 6 & 4 & 8 & 5 & 4 & 6 & 4 & 0 & 0 \\
\hline 0 & 5 & 3 & 4 & 6 & 4 & 0 & 7 & 3 & 0 & 5 & 6 & 4 & 3 & 4 \\
\hline
\end{tabular}

Fig. 3 EVs population in each zone

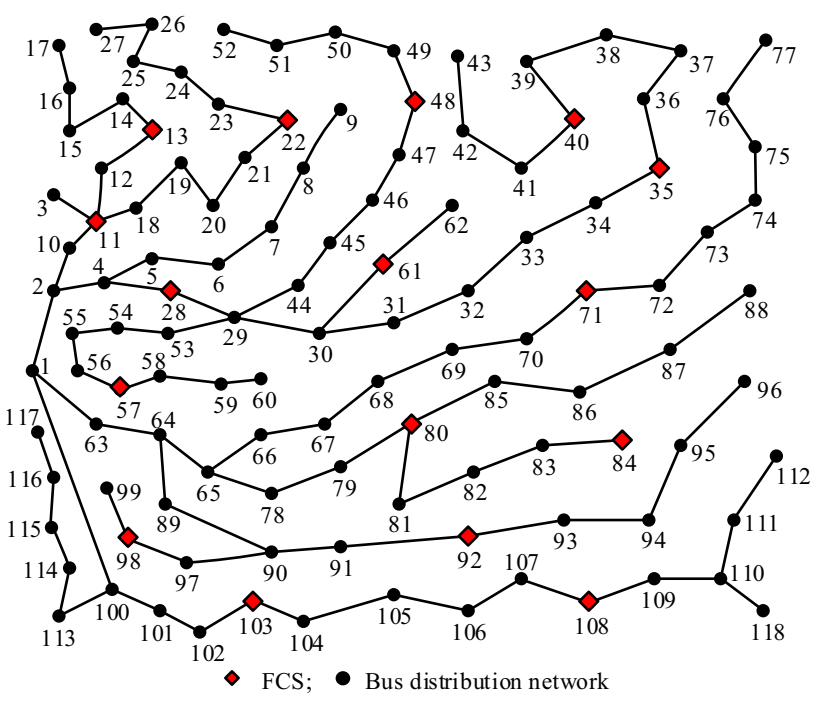

Fig. 4 118-bus distribution network in considered study area

diagram of 118-bus distribution network associated with the considered study area.

The possible placement of 16 FCSs has been assumed to be placed along the main roads of the study area, with constraints of approximately equal distance among the FCSs. Rhombus symbol in Fig. 4 shows the locations of possible CSs. The distribution system and CS parameters used in the proposed system are listed in Table 2.

The charging probability of EVs $\left(C_{P E V}\right)$ in each hour during the day is shown in Fig. 5. It is assumed that EVs are charged at their respective FCSs from 05:00 to 21:00 a day.

To verify the effectiveness and feasibility of the proposed optimal planning of FCSs and DGs in the radial distribution network, three different scenarios are proposed to analyze.

Table 2 Main study parameters [23]

\begin{tabular}{ll}
\hline Parameter & Value \\
\hline$N_{T E V}$ & 1632 \\
$N_{Y}$ & 5 \\
$N_{P C}$ & 16 \\
$S E C$ & $0.142 \mathrm{kWh} / \mathrm{km}$ \\
$C_{E P}$ & $87.7 \$ / \mathrm{MWh}$ \\
$C_{\text {lan }}$ & $240 \$ / \mathrm{M}^{2}$ per year \\
$C_{\text {init }}$ & $70000 \$$ \\
$C_{\text {con }}$ & $208.33 \$ / \mathrm{kW}$ \\
$P_{C}$ & $96 \mathrm{~kW}$ \\
\hline
\end{tabular}




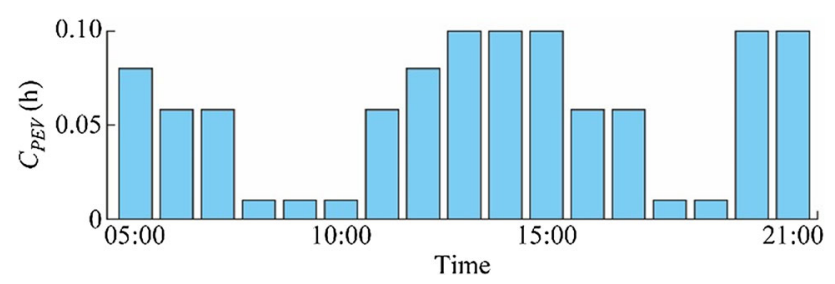

Fig. 5 Variation of $C_{P E V}$

\subsubsection{Scenario 1: optimal placement of FCSs in coupled electrical distribution and transportation network}

The optimal number and locations of FCSs have been determined by considering the minimization of EV user's cost, NPL and the MVD in the distribution network. The optimal placement of FCSs is determined considering load variation during four different seasons. The optimization algorithm presented in Fig. 2 is employed to evaluate the fitness function given in (13) against the different number of FCSs in the network. This algorithm determines the optimal capacity and locations of FCSs in the study area. Since, the DGs are not considered in this scenario, the $C_{D G}$ in (13) is zero. The objective function for the different number of FCSs is compared in Fig. 6. From this comparison, the optimal number of FCSs is determined to be 6.

In scenario 1, based on the objective functions to minimize viz. NPL cost, EVUC and MVD, the following three cases are considered. The variation of SDC does not impact significantly on the overall objective function, since the total number of connectors in all CSs is approximately constant. Hence, SDC is not considered as an objective to minimize.

1) Case 1: minimization of NPL cost and MVD

2) Case 2: minimization of NPL cost and EVUC

3) Case 3: minimization of NPL cost, MVD and EVUC

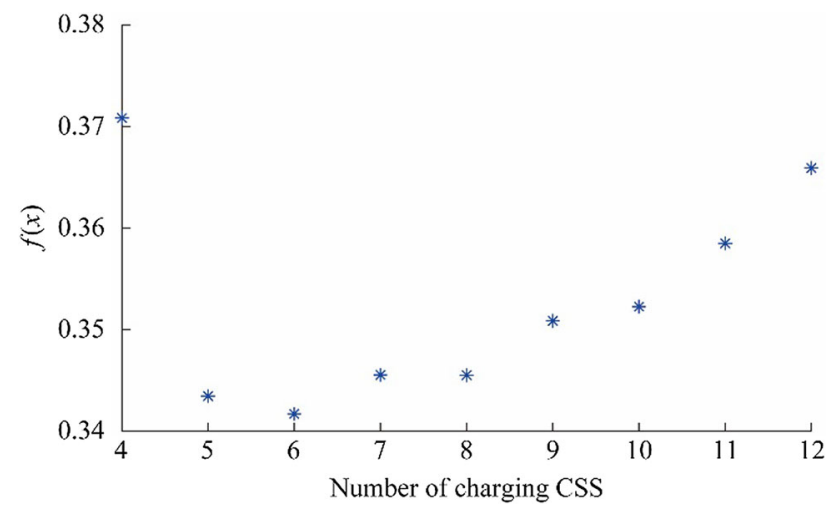

Fig. 6 Optimal number of FCSs in considered coupled electrical distribution and transportation network

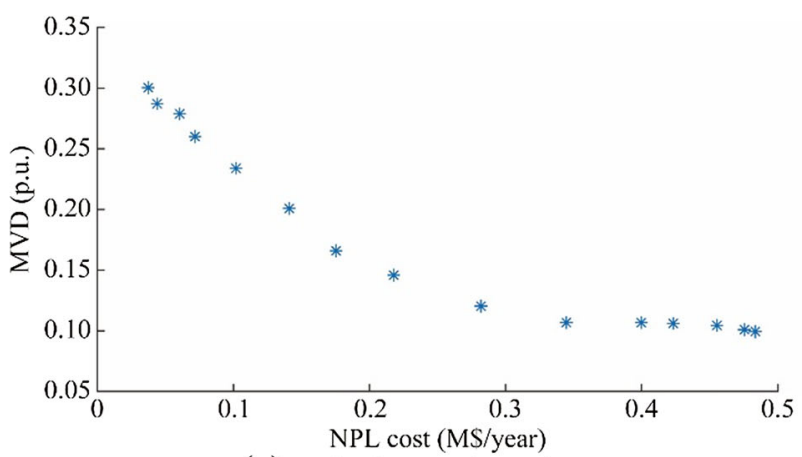

(a) Optimal Pareto-front of case 1

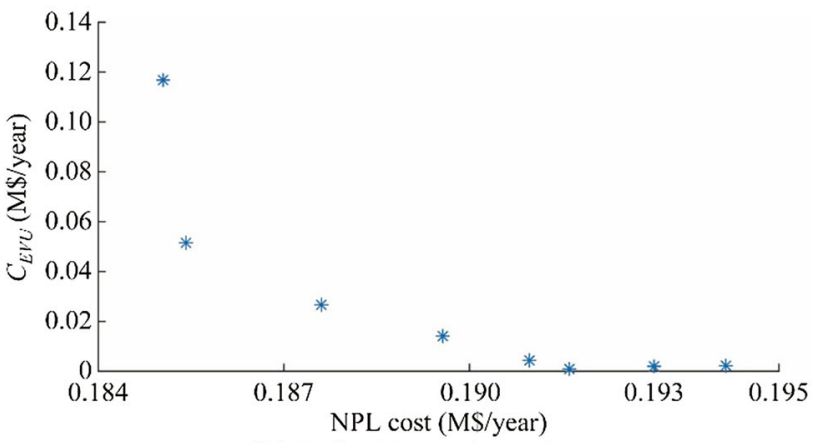

(b) Optimal Pareto-front of case 2

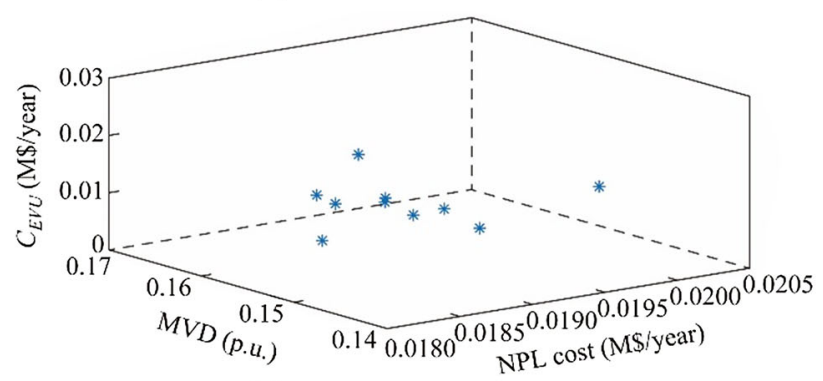

(c) Optimal Pareto-front of case 3

Fig. 7 Optimal Pareto-front plots for scenario 1

The optimal Pareto-front for the minimization of NPL cost, EVUC and MVD simultaneously for all case studies of scenario 1 is shown in Fig. 7.

From the optimal Pareto-front the best compromised solution is obtained using a min-max optimization technique as discussed in [31]. For the obtained compromised or moderate solution, the optimal FCS location and number of EVs connected to FCS for various cases in scenario 1 are presented in Table 3. The optimal objective parameters for scenario 1 are listed in Table 4.

The SDC has been evaluated based on the total number of connectors in each FCS. The SDC, EVUC, NPL cost and MVD are obtained as $2.053 \times 10^{6}(\$), 2.178 \times 10^{4}$ (\$/year), $2.178 \times 10^{5}$ (\$/year) and 0.1459 p.u. in case 1 of scenario 1 . In case 2, it has approximately same SDC and EVUC, NPL cost, and MVD are $1.896 \times 10^{4}$ (\$/year), $1.876 \times 10^{5}(\$ /$ year) and 0.156 p.u. respectively. When three objective 
Table 3 Optimal planning of FCSs for scenario 1

\begin{tabular}{|c|c|c|c|c|c|c|}
\hline \multirow{2}{*}{$\begin{array}{l}\text { FCS } \\
\text { number }\end{array}$} & \multicolumn{2}{|l|}{ Case 1} & \multicolumn{2}{|l|}{ Case 2} & \multicolumn{2}{|l|}{ Case 3} \\
\hline & $\begin{array}{l}\text { FCS } \\
\text { location }\end{array}$ & $\begin{array}{l}\text { No. of } \\
\text { EVs to } \\
\text { FCS }\end{array}$ & $\begin{array}{l}\text { FCS } \\
\text { location }\end{array}$ & $\begin{array}{l}\text { No. of } \\
\text { EVs to } \\
\text { FCS }\end{array}$ & $\begin{array}{l}\text { FCS } \\
\text { location }\end{array}$ & $\begin{array}{l}\text { No. of } \\
\text { EVs to } \\
\text { FCS }\end{array}$ \\
\hline 1 & 92 & 243 & 28 & 307 & 61 & 661 \\
\hline 2 & 40 & 187 & 42 & 83 & 108 & 274 \\
\hline 3 & 98 & 187 & 92 & 330 & 103 & 89 \\
\hline 4 & 61 & 469 & 71 & 358 & 57 & 281 \\
\hline 5 & 28 & 300 & 35 & 307 & 80 & 262 \\
\hline 6 & 108 & 246 & 57 & 247 & 98 & 65 \\
\hline
\end{tabular}

Table 4 Optimal objective parameters for scenario 1

\begin{tabular}{lllll}
\hline Case & $\begin{array}{l}\text { SDC } \\
(\mathrm{M} \$)\end{array}$ & $\begin{array}{l}\text { EVUC } \\
\text { (M\$/year) }\end{array}$ & $\begin{array}{l}\text { NPL cost } \\
\text { (M\$/year) }\end{array}$ & $\begin{array}{l}\text { MVD } \\
\text { (p.u.) }\end{array}$ \\
\hline 1 & 2.053 & 0.02178 & 0.21780 & 0.1459 \\
2 & 2.052 & 0.01896 & 0.18760 & 0.1560 \\
3 & 2.041 & 0.01399 & 0.18857 & 0.1560 \\
\hline
\end{tabular}

parameters are considered in case 3, the SDC, EVUC, NPL cost and MVD are comparatively minimum as compared to case 1 and case 2 of scenario 1 . From Table 4, the optimal values of the SDC, EVUC, NPL cost and MVD in scenario 1 are $2.041 \times 10^{6}, 1.399 \times 10^{4}, 1.8857 \times 10^{5}$ and 0.156 p.u. respectively.

Even after optimal placement of FCSs, the voltage profile of the 118-bus distribution system violates the system voltage constraints. To improve the voltage profile, in next scenario i.e. scenario 2, the optimal planning of DGs is considered in the coupled electrical distribution and transportation network.

\subsubsection{Scenario 2: optimal placement of DGs in proposed study system with the previous optimal FCS load}

Optimal placement of DGs has been considered to improve the voltage profile in proposed distribution system. Objective function (13) considered the DG cost, SDC, EVUC, NPL cost and MVD in distribution system with the optimal FCSs load obtained in case 3 of scenario 1 . The optimal placement of DGs is determined considering load variation during four different seasons. The optimization algorithm presented in Fig. 2 is employed to evaluate the objection function presented in (13) against different number of DGs in the network. This algorithm determines the optimal size and placement of DGs in the network.

The objective function for different number of DGs is compared in Fig. 8. From this comparison the optimal number of DGs is determined to be 4 . In scenario 2 , three

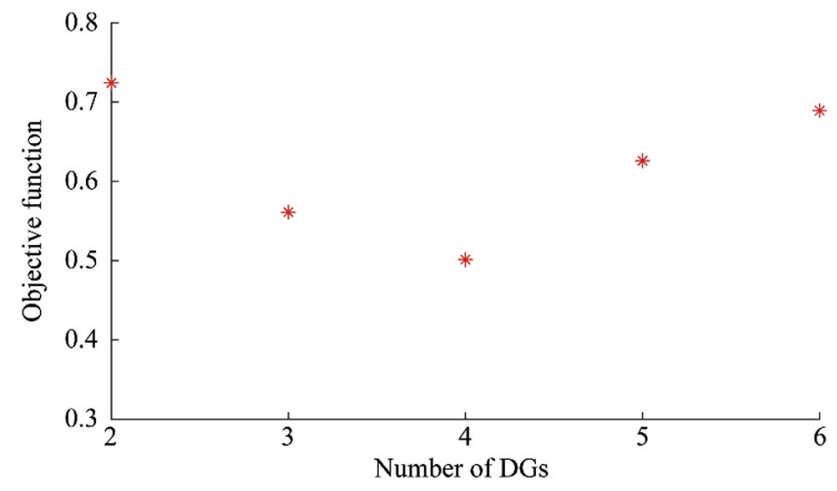

Fig. 8 Optimal number of DGs in the considered coupled electrical distribution and transportation network

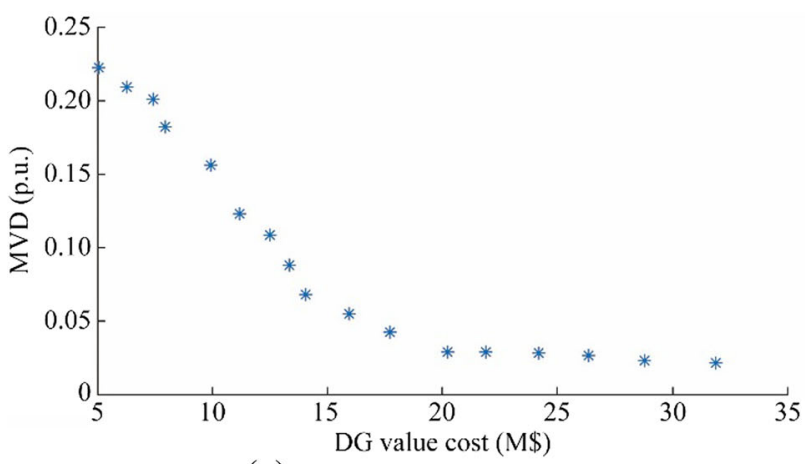

(a) Optimal Pareto-front of case 4

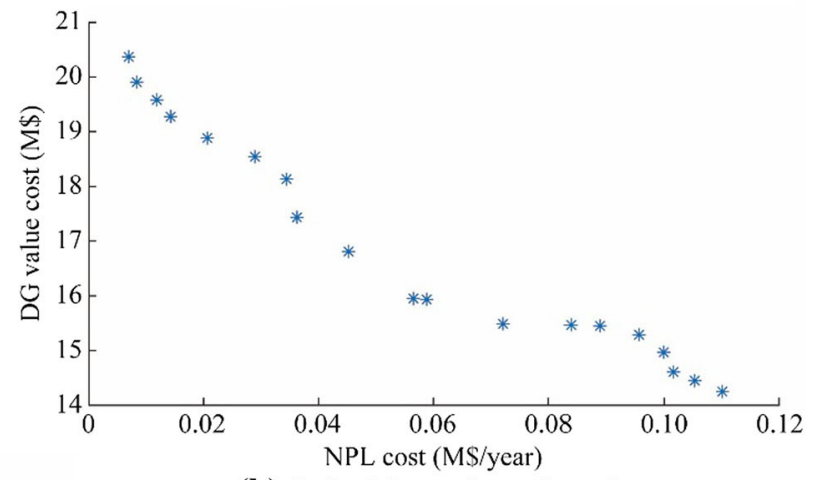

(b) Optimal Pareto-front of case 5

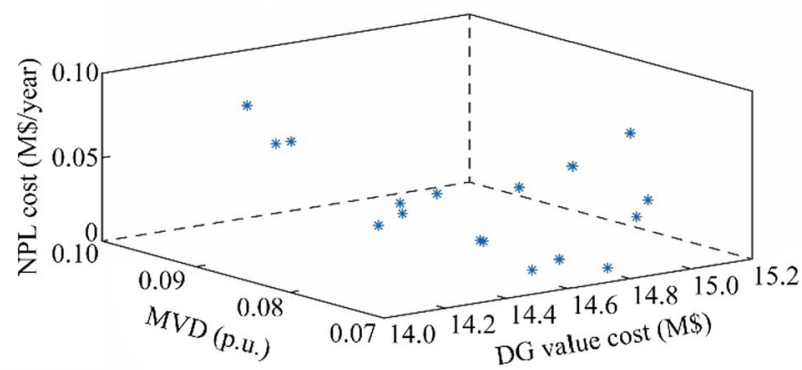

(c) Optimal Pareto-front of case 6

Fig. 9 Optimal Pareto-front plots for scenario 2 
Table 5 Optimal place and sizes of DGs

\begin{tabular}{|c|c|c|c|c|c|c|}
\hline \multirow{2}{*}{$\begin{array}{l}\text { DG } \\
\text { No. }\end{array}$} & \multicolumn{2}{|l|}{ Case 4} & \multicolumn{2}{|l|}{ Case 5} & \multicolumn{2}{|l|}{ Case 6} \\
\hline & $\begin{array}{l}\text { DG } \\
\text { location }\end{array}$ & $\begin{array}{l}\text { DG size } \\
\text { (MW) }\end{array}$ & $\begin{array}{l}\text { DG } \\
\text { location }\end{array}$ & $\begin{array}{l}\text { DG size } \\
\text { (MW) }\end{array}$ & $\begin{array}{l}\text { DG } \\
\text { location }\end{array}$ & $\begin{array}{l}\text { DG size } \\
\text { (MW) }\end{array}$ \\
\hline 1 & 32 & 0.1032 & 40 & 0.1262 & 37 & 0.2000 \\
\hline 2 & 36 & 0.1000 & 42 & 0.1010 & 42 & 0.1996 \\
\hline 3 & 70 & 0.1265 & 72 & 0.1164 & 74 & 0.1982 \\
\hline 4 & 118 & 0.1071 & 111 & 0.0749 & 111 & 0.1896 \\
\hline
\end{tabular}

Table 6 Optimal cost values with DGs placement

\begin{tabular}{llllll}
\hline Case & $\begin{array}{l}\text { SDC cost } \\
(\mathrm{M} \$)\end{array}$ & $\begin{array}{l}\text { EVUC } \\
\text { (M\$/year) }\end{array}$ & $\begin{array}{l}\text { NPL cost } \\
(\mathrm{M} \$ \text { /year })\end{array}$ & $\begin{array}{l}\text { DG cost } \\
(\mathrm{M} \$)\end{array}$ & $\begin{array}{l}\text { MVD } \\
\text { (p.u. })\end{array}$ \\
\hline 4 & 2.041 & 0.01399 & 0.07212 & 14.06 & 0.0681 \\
5 & 2.041 & 0.01399 & 0.05625 & 15.95 & 0.8990 \\
6 & 2.041 & 0.01399 & 0.05651 & 14.82 & 0.0720 \\
\hline
\end{tabular}

cases are conducted to determine the optimal location and size of DGs with the account of the optimal FCSs load obtained in case 3 of scenario 1. The EVUC in scenario 2 is same as case 3 of scenariol and its value is constant.

1) Case 4: minimization of DG value cost and MVD

2) Case 5: minimization of NPL cost and DG value cost

3) Case 6: minimization of DG value cost, MVD and NPL cost

The Pareto-front for different case studies in scenario 2 is shown in Fig. 9.

From the above optimal Pareto fronts the best moderate location and size of DG units are determined using minmax method. The optimal location and size of DG units for different case studies in scenario 2 are presented in Table 5.

From the Pareto-front provided in Fig .8, best compromised objective parameters for the case 4 , case 5 and case 6 are reported in Table 6 .

There are two observations can be made by analyzing the results provided in Table 6 . The first one is that as NPL cost and MVD decreases, the DG cost increases. The NPL cost and MVD directly depend on DGs location and its size. The second one is that SDC and EVUC are constant. In scenario 2, the optimal planning of DGs is determined with the account of optimal FCS load (case 3 of scenario 1) in the electrical distribution system. Therefore the SDC and EVUC are constant in all three cases of scenario 2 .

In case 4, DG cost and MVD are considered for optimal planning of DGs in the electrical distribution system. For which the NPL cost, DG cost and MVD are $7.212 \times 10^{4} \$ /$

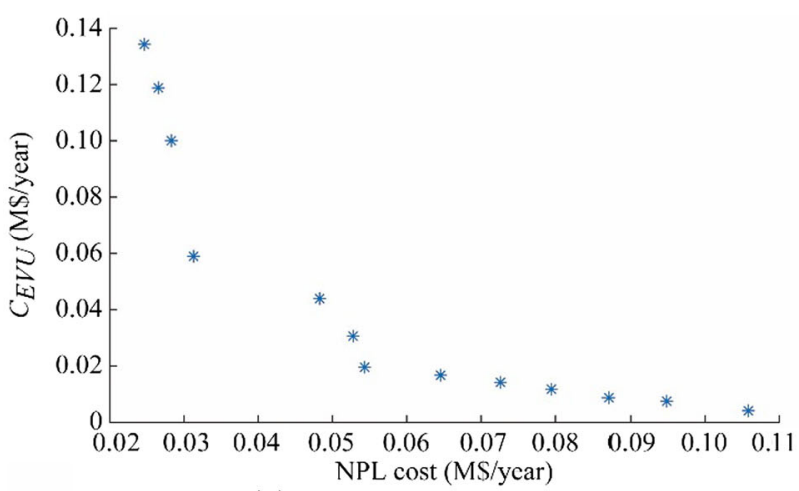

(a) Optimal Pareto-front of case 7

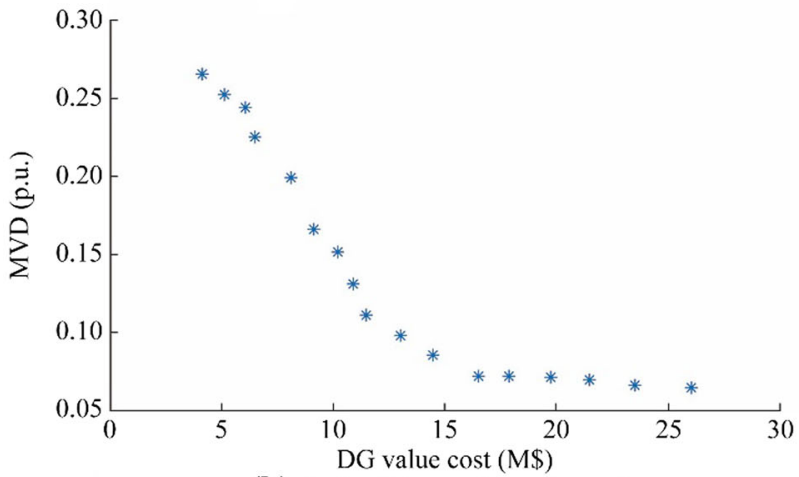

(b) Optimal Pareto-front of case 9

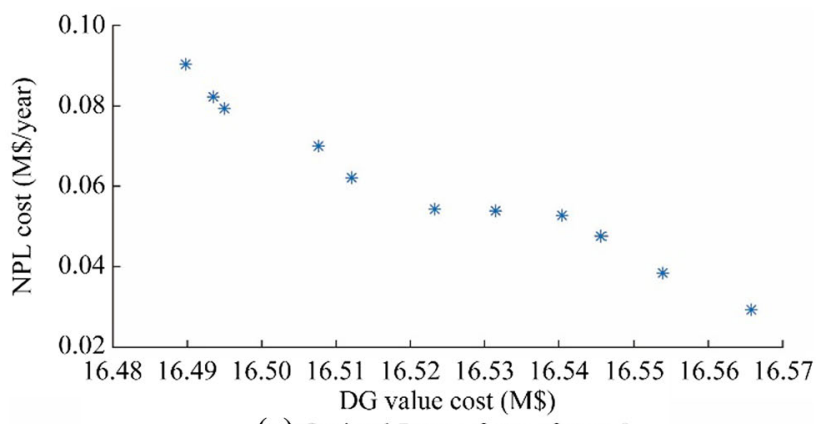

(c) Optimal Pareto-front of case 8

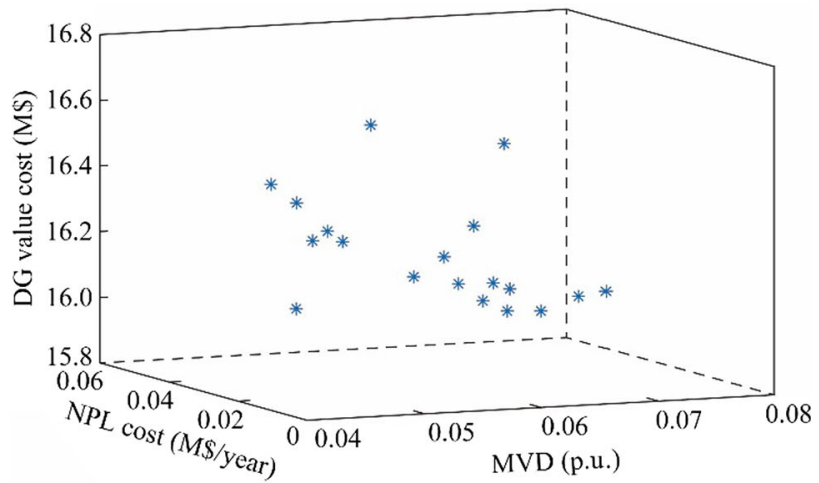

(d) Optimal Pareto-front of case 10

Fig. 10 Optimal Pareto-front plots for scenario 3

year $14.06 \mathrm{M} \$, 0.0681$ p.u. respectively. Similarly, the NPL cost, DG cost, and MVD are $5.625 \times 10^{4} \$ /$ year, 15.95 M\$, 0.899 p.u. for case 5. Furthermore, in case 6, three 
Table 7 Optimal planning of FCSs in scenario 3

\begin{tabular}{|c|c|c|c|c|c|c|c|c|}
\hline \multirow{2}{*}{$\begin{array}{l}\text { FCS } \\
\text { No. }\end{array}$} & \multicolumn{2}{|l|}{ Case 7} & \multicolumn{2}{|l|}{ Case 8} & \multicolumn{2}{|l|}{ Case 9} & \multicolumn{2}{|l|}{ Case 10} \\
\hline & $\begin{array}{l}\text { FCS } \\
\text { location }\end{array}$ & $\begin{array}{l}\text { No. of EVs to } \\
\text { FCS }\end{array}$ & $\begin{array}{l}\text { FCS } \\
\text { location }\end{array}$ & $\begin{array}{l}\text { No. of EVs to } \\
\text { FCS }\end{array}$ & $\begin{array}{l}\text { FCS } \\
\text { location }\end{array}$ & $\begin{array}{l}\text { No. of EVs to } \\
\text { FCS }\end{array}$ & $\begin{array}{l}\text { FCS } \\
\text { location }\end{array}$ & $\begin{array}{l}\text { No. of EVs to } \\
\text { FCS }\end{array}$ \\
\hline 1 & 28 & 245 & 61 & 428 & 13 & 94 & 83 & 576 \\
\hline 2 & 71 & 570 & 48 & 200 & 103 & 165 & 28 & 251 \\
\hline 3 & 22 & 245 & 40 & 76 & 71 & 591 & 80 & 156 \\
\hline 4 & 98 & 136 & 71 & 376 & 28 & 236 & 103 & 254 \\
\hline 5 & 80 & 354 & 92 & 276 & 80 & 356 & 48 & 249 \\
\hline 6 & 103 & 82 & 103 & 276 & 22 & 189 & 92 & 146 \\
\hline
\end{tabular}

Table 8 Optimal planning of DGs in scenario 3

\begin{tabular}{|c|c|c|c|c|c|c|c|c|}
\hline \multirow[t]{2}{*}{ DG No. } & \multicolumn{2}{|l|}{ Case 7} & \multicolumn{2}{|l|}{ Case 8} & \multicolumn{2}{|l|}{ Case 9} & \multicolumn{2}{|l|}{ Case 10} \\
\hline & DG location & DG size $(\mathrm{MW})$ & DG location & DG size (MW) & DG location & DG size (MW) & DG location & DG size $(\mathrm{MW})$ \\
\hline 1 & 95 & 0.0711 & 83 & 0.0867 & 97 & 0.0698 & 36 & 0.2000 \\
\hline 2 & 59 & 0.0611 & 43 & 0.0764 & 30 & 0.1074 & 74 & 0.1749 \\
\hline 3 & 93 & 0.0751 & 28 & 0.0885 & 103 & 0.0626 & 83 & 0.1498 \\
\hline 4 & 32 & 0.1811 & 114 & 0.1516 & 46 & 0.0935 & 11 & 0.1947 \\
\hline
\end{tabular}

objective parameters are considered for optimal planning of DGs in the distribution system. Because of the participation of three objective parameters in optimization processes, case 6 provided a best economical solution as compared to case 4 and case 5 in scenario 2. The optimal values of the NPL cost, DG cost, and MVD are $5.651 \times 10^{4}$ \$/year $14.82 \mathrm{M} \$, 0.072$ p.u. respectively. It can be observed that case 6 of scenario 2 gives best economical solution as compared to the case 4 and case 5. Furthermore, to minimize the NPL cost, DG cost and MVD, the simultaneous placement of FCSs and DGs in coupled electrical distribution and transportation network is considered in scenario 3 .

\subsubsection{Scenario 3: simultaneous placement of FCSS and DGs in coupled electrical distribution and transportation network}

In this scenario, the FCSs and DGs are simultaneously placed in the distribution network, with the objective of decreasing the EVUC, NPL cost, DG cost and MVD. In scenario 3, the following four different cases are considered for the simultaneous optimal placement of FCSs and DGs in coupled electrical distribution and transportation network.

1) Case 7: minimization of NPL cost and EVUC

2) Case 8: minimization of DG value cost and MVD

3) Case 9: minimization of NPL cost and DG value cost

4) Case 10: minimization of DG value cost, MVD and NPL cost

The algorithm presented in Fig. 2 is employed to evaluate the fitness function given in equation (13) against the different number of FCSs and DGs in the distribution network. This algorithm determines the optimal size and placement of FCSs and DGs in the distribution network, for the same number of FCSs and DGs as in scenario 1 and scenario 2 respectively. The Pareto-front for minimization of NPL cost, DG cost, EVUC and MVD for various case studies of scenario 3 are shown in Fig. 10.

The optimal capacity and location of FCSs and DGs are listed in Tables 7 and 8.

Table 9 Optimal cost values in scenario 3

\begin{tabular}{clllll}
\hline Case & SDC cost $(\mathrm{M} \$)$ & EVUC $(\mathrm{M} \$$ /year $)$ & NPL cost $(\mathrm{M} \$$ /year) & DG cost (M\$) & MVD (p.u.) \\
\hline 7 & 2.038 & 0.019580 & 0.054320 & 17.950 & 0.0998 \\
8 & 2.041 & 0.023590 & 0.063120 & 16.520 & 0.0720 \\
9 & 2.040 & 0.019690 & 0.053890 & 16.530 & 0.0899 \\
10 & 2.0101 & 0.005963 & 0.054323 & 15.951 & 0.0613 \\
\hline
\end{tabular}


Table 10 Optimal cost comparison results in three scenarios

\begin{tabular}{clllll}
\hline Case & SDC $(\mathrm{M} \$)$ & EVUC $($ M\$year) & NPL cost $(\$ /$ year $)$ & DG cost (M\$) & MVD (p.u.) \\
\hline 10 & 2.0101 & 0.0059636 & $0.054323 \times 10^{4}$ & 15.9510 & 0.0613 \\
6 & 2.0410 & 0.0139960 & $0.056517 \times 10^{4}$ & 16.5233 & 0.0721 \\
3 & 2.0410 & 0.0139960 & $1.885700 \times 10^{5}$ & - & 0.1560 \\
\hline
\end{tabular}

From the obtained Pareto fronts, the moderate solution is determined using the min-max technique.

Table 9 presents the optimal objective parameters of different cases of scenario 3 . In case 7, optimized values of NPL cost and EVUC are $5.432 \times 10^{4} \$ /$ year and $1.958 \times$ $10^{4}$ \$/year respectively, for which the DG cost and MVD are $17.95 \mathrm{M} \$$ and 0.0998 p.u.. In case 8 , the optimized values of the DG cost and MVD are $16.52 \mathrm{M} \$$ and $0.072 \mathrm{p}$. u., for which EVUC and NPL cost is maximum, i.e., 2.359 $\times 10^{4} \$$ year and $6.312 \times 10^{4} \$ /$ year. Similarly, the optimized values of the DG cost and NPL cost are $16.53 \mathrm{M} \$$ and $5.389 \times 10^{4} \$ /$ year in case 9 , for which the optimal EVUC and MVD are $1.969 \times 10^{4} \$ /$ year and 0.0899 p.u. respectively. Furthermore, three objectives, i.e., MVD, NPL cost and DG cost optimized values are 0.0613 p.u., $5.4323 \times 10^{4} \$ /$ year and $15.951 \mathrm{M} \$$ respectively. In scenario 3 , the NPL cost and EVUC are considerably reduced for approximately same investment. The NPL cost and EVUC are variable ones, with the reduction of this losses result in benefit to both the EV users and CS owners.

The optimal objective parameters namely NPL cost, MVD, EVUC and DG cost for the best cases (case 3 in scenario 1 ; case 6 in scenario 2; and case 10 in scenario 3 ) in the above three different scenarios are presented in Table 10. From Table 10, it is clear that case 10 gives best compromised solution as compared to the other cases of scenario 3 .

In scenario 3, the EVUC, NPL cost and MVD are significantly reduced as compared to the scenario 2 and scenario 1. The simultaneous planning of FCSs and DGs in the coupled electrical distribution and transportation network of case 10 has a $60.7 \%$ and $14.97 \%$ reduction of MVD as compared to the case 3 and case 6 . Also, the NPL cost reduced by $71.2 \%$ and $3.8 \%$ by case 10 as compared to the case 3 and case 6. Furthermore, there is a $57.3 \%$ reduction of EVUC in case 10 as compared to other cases. Therefore the proposed method is capable of providing the best economical solution for the simultaneous optimal placement of FCS and DGs in coupled electrical distribution and transportation network.

\section{Conclusion}

The massive penetration of EVs causes a negative impact on the power grid. A large number of EVs simultaneously connected to the grid causes more NPLs and large voltage deviation at far away buses from the sources. To improve the bus voltage profile in the presence of EVCSs in distribution network, this paper considered simultaneous placement of DGs and FCSs. Simulation results show the importance of optimal concurrent placement of both FCSs and DGs in the distribution system. In the proposed approach, optimal planning of FCSs and optimal planning of DGs with the account of optimal FCSs load are compared to simultaneous planning of FCSs and DGs in coupled electrical distribution and transportation network. The simultaneous placement of FCSs and DGs results in more reduction in EVUC and NPL cost for the same SDC and DG value investment. The EVUC and NPL cost are variable with respect to time. Hence, the reduction in this cost will be beneficial for both EV and CS owners. The optimal simultaneous placement of both FCSs and DGs in distribution system provides significant benefits to all parts involved.

Open Access This article is distributed under the terms of the Creative Commons Attribution 4.0 International License (http:// creativecommons.org/licenses/by/4.0/), which permits unrestricted use, distribution, and reproduction in any medium, provided you give appropriate credit to the original author(s) and the source, provide a link to the Creative Commons license, and indicate if changes were made.

\section{References}

[1] Rajkumar (2013) Global EV outlook 2013-understanding the electric vehicle landscape to 2020. International Energy Agency, Clean Energy Ministerial, and Electric Vehicles Initiative

[2] Duvall M, Knipping E (2007) Environmental assessment of plug-inhybrid electric vehicles. EPRI, Palo Alto

[3] $\mathrm{Xu} \mathrm{Z,} \mathrm{Su} \mathrm{W,} \mathrm{Hu} \mathrm{Z} \mathrm{et} \mathrm{al} \mathrm{(2016)} \mathrm{A} \mathrm{hierarchical} \mathrm{framework} \mathrm{for}$ coordinated charging of plug-In electric vehicles in China. IEEE Trans Smart Grid 7(1):428-438

[4] Etezadi-Amoli M, Choma K, Stefani J (2010) Rapid-charge electric-vehicle stations. IEEE Trans Power Deliv 25(3):18831887

[5] Fox GH (2013) Electric vehicle charging stations: are we prepared? IEEE Ind Appl Mag 19(4):32-38 
[6] Garas D, Collantes GO, Nicholas MA (2016) City of vancouver EV infrastructure strategy report. Working Paper - UCD-ITSWP-16-04. https://phev.ucdavis.edu/wp-content/uploads/2017/ 05/2016-UCD-ITS-WP-16-04.pdf. Accessed 29 December 2018

[7] Sadeghi-Barzani P, Rajabi-Ghahnavieh A, Kazemi-Karegar H (2014) Optimal fast charging station placing and sizing. Appl Energy 125:289-299

[8] Liu Z, Wen F, Ledwich G (2013) Optimal planning of electricvehicle charging stations in distribution systems. IEEE Trans Power Deliv 28(1):102-110

[9] Miralinaghi M, Keskin BB, Lou Y et al (2017) Capacitated refueling station location problem with traffic deviations over multiple time periods. Netw Spat Econ 17(1):129-151

[10] Zhang H, Moura SJ, Hu Z et al (2018) PEV fast-charging station siting and sizing on coupled transportation and power networks. IEEE Trans Smart Grid 9(4):2595-2605

[11] Zheng Y, Dong Z, Xu Y et al (2014) Electric vehicle battery charging/swap stations in distribution systems: comparison study and optimal planning. IEEE Trans Power Syst 29(1):221229

[12] Wang G, Xu Z, Wen F et al (2013) Traffic-constrained multiobjective planning of electric-vehicle charging stations. IEEE Trans Power Deliv 28(4):2363-2372

[13] Schneider K, Gerkensmeyer C, Kintner-Meyer M et al (2008) Impact assessment of plug-in hybrid vehicles on pacific northwest distribution systems. In: Proceedings of 2008 IEEE power and energy society general meeting, Pittsburgh, USA, 20-24 July 2008, 6 pp

[14] Zhang L, Shaffer B, Brown T et al (2015) The optimization of DC fast charging deployment in California. Appl Energy 157:111-122

[15] Hess A, Malandrino F, Reinhardt MB et al (2012) Optimal deployment of charging stations for electric vehicular networks. In: Proceedings of 1 st workshop urban networking ACM, Nice, France, 10 December 2012, 6 pp

[16] Boulanger AG, Chu AC, Maxx S et al (2011) Vehicle electrification: status and issues. Proc IEEE 99(6):1116-1138

[17] Xiong Y, Gan J, An B et al (2018) Optimal electric vehicle fast chargingstation placement based on game theoretical framework. IEEE Trans Intell Transp Syst 19(8):2493-2504

[18] Guo S, Zhao H (2015) Optimal site selection of electric vehicle charging station by using fuzzy TOPSIS based on sustainability perspective. Appl Energy 158(15):390-402

[19] Awasthi A, Venkitusamy K, Sanjeevikumar P et al (2017) Optimal planning of electric vehicle charging station at the distribution system using hybrid optimization algorithm. Appl Energy 133:70-78

[20] Liu H, Yang M, Zhou M et al (2018) An integrated multi-criteria decision making approach to location planning of electric vehicle charging stations. IEEE Trans Intell Transp Syst. https:// doi.org/10.1109/tits.2018.2815680

[21] Zhang H, Moura SJ, Hu Z (2018) Joint PEV charging network and distributed PV generation planning based on accelerated generalized benders decomposition. IEEE Trans Transp Electrif. https://doi.org/10.1109/tte.2018.2847244

[22] Erdinc O, Tascikaraoglu A, Paterakis NG et al (2017) Comprehensive optimization model for sizing and siting of DG units, EV charging stations and energy storage systems. IEEE Trans Smart Grid 9(4):3871-3882

[23] Rajabi-Ghahnavieh A, Sadeghi-Barzani P(2017) Optimal zonal fast-charging station placement considering urban traffic circulation. IEEE Trans Veh Technol 66(1):45-56

[24] Ameli A, Bahrami S, Khazaeli F et al (2014) A multiobjective particle swarm optimization for sizing and placement of DGs from DG owner's and distribution company's viewpoints. IEEE Trans Power Deliv 29(4):1831-1840

[25] Mitra J, Vallem MR, Singh C (2016) Optimal deployment of distributed generation using a reliability criterion. IEEE Trans Ind Appl 52(3):1989-1997

[26] Abdelsalam AA, Zidan AA, El-Saadany EF (2015) Optimal DG allocation in radial distribution systems with high penetration of non-linear loads. Electr Power Compon Syst 43(13):1487-1497

[27] Weis A, Jaramillo P, Michalek J (2014) Estimating the potential of controlled plug-in hybrid electric vehicle charging to reduce operational and capacity expansion costs for electric power systems with high wind penetration. Appl Energy 115:190-204

[28] McPhail D (2014) Evaluation of ground energy storage assisted electric vehicle DC fast charger for demand charge reduction and providing demand response. Renew Energy 67:103-108

[29] Yammani C, Maheswarapu S, Matam SK (2011) Enhancement of voltage profile and loss minimization in distribution systems using optimal placement and sizing of power system modeled DGs. J Electr Syst 7(4):448-457

[30] Deb K, Pratap A, Agarwal S et al (2002) A fast and elitist multiobjective genetic algorithm: NSGA-II. IEEE Trans Evolut Comput 6(2):182-197

[31] Srinivas N, Deb K (1994) Multiobjective optimization using nondominated sorting in genetic algorithms. J Evolut Comput 2 (3):221-248

Gurappa BATTAPOTHULA obtained his B.Tech. in Electrical and Electronics Engineering, 2012 and M.Tech. in Electrical Power Systems, 2015 from Jawaharlal Nehru Technological University, Ananthapuramu, India. Currently, he is working towards Ph.D. degree in Power Systems at National Institute of Technology, Warangal, India. His research areas include state estimation, optimization techniques, meta-heuristic techniques, optimal planning of electric vehicles in distribution system.

Chandrasekhar YAMMANI received B.Tech. degree in Electrical and Electronics Engineering from Jawaharlal Nehru Technological University, Hyderabad, India, in 2007. He possessed M.Tech. and Ph. D. degrees in Power Systems Engineering from the National Institute of Technology Warangal (NITW), Warangal, India, in 2009 and 2015, respectively. He completed post-doctorate fellowship from UWS, Scotland under Erasmus Mundus Program in 2018. He has been working as an assistant professor in Electrical Engineering Department of NITW since March 2012. His research areas include power system operation and control, planning studies of distribution generation and renewable energy resources in power systems, smart grids, microgrids, optimization techniques, meta-heuristic techniques, blockchain Technologies, electric vehicles, reliability and resilience studies of power systems.

Sydulu MAHESWARAPU obtained his B.Tech. in Electrical Engineering, 1978, M.Tech. in Power Systems, 1980, and Ph.D. in Electrical Engineering Power Systems, 1993 from Regional Engineering College Warangal, Andhra Pradesh, India. Currently, he is a professor of Electrical Engineering at National Institute of Technology, Warangal (formerly RECW). His research interests include realtime power system operation and control, ANN, fuzzy logic, and genetic algorithm applications in power systems, distribution system studies, economic operation, reactive power planning and management. 